\title{
CLINICAL COMPARATIVE STUDY OF SUMATRIPTAN VERSUS ERGOTAMINE THERAPY IN MIGRAINE
}

\author{
K. V. Giriraja1, Pavitra Chandrashekar², Bindumathi P. $L^{3}$ \\ ${ }_{1}^{1}$ Professor, Department of General Medicine, Sapthagiri Medical College, Bangalore. \\ 2Private Consultant, Ajisha Dental Clinic, Bangalore. \\ 3Professor \& HOD, Department of General Medicine, Sapthagiri Medical College, Bangalore.
}

\section{ABSTRACT}

\section{BACKGROUND}

Migraine is a common neurological problem accounting for large morbidity and disability. Ergotamine and triptans are mainly used to terminate the attack of severe migraine. To study the clinical comparison between sumatriptan and ergotamine in migraine patients.

AIM

This study compared the safety efficacy and pharmacoeconomics of triptans verses ergotamine therapy.

\section{MATERIALS AND METHODS}

Study sample included 100 patients of either gender aged 18 to 65 yrs reporting in Neurology OPD in Sapthagiri Institute of Medical Sciences, Bangalore. The study was conducted from January 2014 to December 2014.

\section{RESULTS}

Triptans was found to be more efficacious than ergotamine in curing an attack of migraine and its associated symptoms, but looking into the contraindications, side effects and cost of the triptans, there has been limitations in its prescriptions as well as use.

\section{CONCLUSION}

Ergotamine is more effective in sustained pain relief with less recurrence rate, less adverse effects and more economical compared to sumatriptan.

\section{KEYWORDS}

Migraine, Headache, Sumatriptan, Ergotamine.

HOW TO CITE THIS ARTICLE: K. V. Giriraja, Pavitra Chandrashekar, Bindumathi P. L. "Clinical Comparative Study of Sumatriptan Versus Ergotamine Therapy in Migraine." Journal of Evolution of Medical and Dental Sciences 2015; Vol. 4, Issue 100, December 14; Page: 16548-16550, DOI: 10.14260/jemds/2015/2462

\section{INTRODUCTION}

As new molecules come to market, they should be more effective in clinical response, have less side effects, less drug interactions, less adverse effects and are more cost effective. Many drugs are available for the treatment of migraine; 5-HT IB/ID agonist; triptans are the new molecules that has come into market. There are many conventional therapies to treat this disorder. Migraine is a complex disorder characterized by recurrent episodes of headache, most of them unilateral and in some cases associated with visual or sensory symptoms collectively known as an aura that arise most often before the head pain, but that may occur during or after. Migraine is most common in women and has a strong genetic component. Typical symptoms of migraine include throbbing or pulsative headache with moderate-to-severe pain that intensify with movement or physical activity.

Unilateral or localised pain can occur in the frontotemporal or ocular area, but the pain can be felt in and around the head and neck region. Pain builds up over a period of one to two hours progressing posteriorly and becoming diffuse. $1,2,3$

Financial or Other, Competing Interest: None.

Submission 23-11-2015, Peer Review 24-11-2015,

Acceptance 08-12-2015, Published 14-12-2015.

Corresponding Author:

Dr. K. V. Giriraja,

No. 24, A-3, Shreya Apartments,

$3^{\text {rd }}$ Cross, Jaladarshini Layout,

R.M.V., $2^{\text {nd }}$ Stage,

Bangalore-560094.

E-mail: drgiriraja@gmail.com

DOI:10.14260/jemds/2015/2462
Headache lasts for 4 to $72 \mathrm{hrs}$. The other associated symptoms of migraine are nausea $80 \%$, vomiting $50 \%$ including anorexia and food intolerance and light headedness, sensitivity to light and sound. Features of migraine may precede or accompany the headache phase or may occur in isolation.

Usually develops over 5 to 20 minutes and lasts less than 60 minutes. Most commonly visual, but can be sensory motor or any combination of these. Visual symptoms can be positive or negative. The most common positive visual phenomena is scintillating scotoma. Clinical signs in mirgarine includes cranial or cervical muscle tenderness, Horner Syndrome, conjectival injection, tachycardia or bradycardia, hypertension or hypotension, hemisensory or hemiparesis.3,4,5

The mechanism of migraine remains incompletely understood. Vascular theory proposed in the 1940 and 1950 to explain the pathophysiology of migraine headache. Ischemia induced by intracranial vasoconstriction is responsible for the aura of migraine and the rebound of vasodilatation and activation of perivascular nerves resulted in headache. This theory was based on the following three observations; extracranial vessel become distended and pulsatile during headache; stimulation of intracranial vessels in an awake person includes headache; vasoconstrictors (Ergots) improve the headache whereas vasodilators (Nitro glycerine) provoke an attack.5,6,7

Neurovascular theory holds that a complex series of neural and vascular events initiates migraine. According to this theory, migraine is primarily a neurogenic process with secondary changes in cerebral perfusion. $2,4,5$ 


\section{Cortical Spreading Depression}

In 1994, Leo proposed the theory of cortical spreading depression to explain the mechanism of headache with aura CSD is a well-defined wave of neuronal excite in the cortical grey matter that spreads from its site of origin at the rate of 2 to $6 \mathrm{~mm}$ per mints. ${ }^{5,6}$

\section{Vasoactive Substances and Neurotransmitters}

Perivascular nerve activities also results in release of substance such as substance $\mathrm{P}$, neurokinin $\mathrm{A}$ and nitric oxide which interact with the blood vessels to produce dilation protein extravasation and sterile inflammation. 4,5

\section{Migraine Centre}

A potential migraine centre in the brain stem has been proposed based on the PET scan results.

\section{Brain Stem Activation}

PET scan in patients having an acute migraine headache demonstrates activation of contralateral pons even after medications abort the pain.

\section{Cutaneous Allodynia}

Burstein described the phenomenon of cutaneous allodynia, in which secondary pain pathways of the trigeminothalamic system become sensitised during a migrainous episode. This observation demonstrates that along with the previously described neurovascular events, sensitization of the centre pathways in the brain, mediates the pain of migraine.5,6,7

\section{Dopamine Pathways}

Some authors have proposed dopaminergic basis for migraine. In 1977, Sicuteri postulated that a state of dopaminergic state of hypersensitivity is present in patients with migraine.8,9,10

\section{Magnesium Deficiency \\ Another theory proposes that deficiency of magnesium in brain triggers a chain of events starting with platelet aggression resulting in release of 5-HT, which is a vasoconstrictor. ${ }^{11,12,13}$}

\section{Endothelial Dysfunction}

Nitric oxide released by microglial is a potentially cytotoxic proinflammatory mediator initiating and maintaining brain inflammation. $13,14,15$

\section{Serotonin and Migraine}

Serotonin receptors are believed to be the most important receptor in the headache pathway. All the currently available triptans are selective 5-HT IB/ID agonist. These agents decrease the headache by abolition in the neuropeptide release in the periphery and blocking neurotransmission by acting on second order neurons in the trigeminal system. ${ }^{16,17,18}$

The present study was done to compare the safety, efficacy and cost effectives of sumatriptan and ergotamine.

\section{MATERIALS AND METHODS}

Institutional Ethical committee clearance was taken

\section{Inclusion criteria}

Study sample included patients of either gender aged 18 to 65 yrs reporting in neurology OPD in Sapthagiri Institute of Medical Sciences Bangalore. The study was conducted from January 2014 to December 2014. 100 patients diagnosed with moderate to severe migraine according to international headache society criteria were divided into two groups randomly, containing 60 and 40 patients in group A and group $B$ respectively.

\section{Exclusion Criteria}

Patients with IHD, congestive heart disease uncontrolled hypertension were excluded also patients having history of epilepsy, basilar migraine, pregnant or lactating mothers were also excluded.

Group A patients were given sumatriptan 15 mgs and Group B patents received ergotamine $1 \mathrm{mg}$ tablets maximum 6 tablets. The next day of taking the drug follow up visit was done. The following outcome measures were defined for the analysis.

\section{Pain Relief}

Reduction of headache severity from moderate or severe at base line to mild or none at 2 hours

\section{Pain free}

Complete abolition of head ache at $2 \mathrm{hrs}$

Twenty Four hour sustained pain relief: Headache relief at two hours with no recurrence and no use of additional medication from 2 to $24 \mathrm{hrs}$ after the initial dose.

Headache recurrence within 24 hours: a return to headache severity of grade 2 or 3 in patients showing an initial response at two hours

Chi- square test was used $\mathrm{p}$ value $<0.5$ was considered as significant.

\section{RESULTS}

The response to drugs was noted, data tabulated and analysed statistically.

Pain free at 2 hrs: complete abolition of headache at $2 \mathrm{hrs}$.

a. Table 1: Shows the number of percentage of patients that were pain free, i.e. complete abolition of headache to 0.5 , 1.0, 1.5 at two hrs after sumatriptan and ergotamine therapy. Statistically significant difference was found at 2 hours with $p$ value 0.005 .

b. Pain relief at two hours: reduction of headache severity from moderate or severe at baseline to mild or none at 2 hours. Table 2: shows the number and percentage of patients who were relieved of pain, i.e. headache severity reduced from moderate-to-severe-to-mild or none 0.5 , $1.0,1.5$ at two hrs. Statistically significant difference was found at 1 hour, 1.5 hour and at 2 hour with $\mathrm{p}$ value $0.029,0.002$ and 0.0024 respectively.

c. Recurrence of headache within $24 \mathrm{hrs}$ : a return to headache severity of grade 2 or 3 in patients showing an initial response of $2 \mathrm{hrs}$. Table 3.

Table 3: The number of percentage of patients who reported occurrence of headache with $24 \mathrm{hrs}$, i.e. a return to headache severity of grade 2 or 3 in patients who showed an initial response at two hrs, which was found to be lesser with ergotamine therapy as compared to sumatriptan therapy. Statistically, however, the difference was not significant.

Our study shows that effect of $24 \mathrm{hrs}$ sustained pain relief was better in ergotamine group compared to sumatriptan group.

\section{DISCUSSION}

Freedom from headache and headache relief is higher in sumatriptan, but recurrence of headache within $24 \mathrm{hrs}$ and $24 \mathrm{hr}$ sustained pain relief was better with ergotamine group compared to triptans group. Our study also shows that side effects were less in ergotamine therapy to sumatriptan; the risk of drug interaction was also more with sumatriptan. The adverse effects in sumatriptan group are as follows: $20 \%$ of the patients had confusion, $10 \%$ blurred vision, $6 \%$ palpitation, $5 \%$ sweating, $4 \%$ muscle cramps; whereas in ergotamine group $10 \%$ of the patients had nausea, vomiting or diarrhoea; 
$6 \%$ had hypertension and tachycardia and $4 \%$ had muscle cramps. Cost of aborting the acute migraine attack is rupees 40 for sumatriptan group as compared to rupees 6 for ergotamine group. India is a developing country, $25 \%$ live below poverty line. $7,8,9$ each day earning those live below poverty line is 33 rupees per day.

The prevalence of headache is high in India, majority of the headache patients are migraine patients. Most of the patients visit government hospitals for headache relief. India spent the least amount on health care; the government of India spent less than 2\% GDP on health. ${ }^{10,11,12,13}$ This is lesser than sub-Saharan countries. Hence, conventional ergotamine therapy can be made available in government hospital and physician in general hospital can continue to prescribe the conventional therapy rather the sumatriptan. Patients suffering from headache believe that they are not suffering from any major disorder and hence land up in Government Hospitals. Very few patients approach Private Hospital. Hence making available cheaper and effective less adverse effect producing drugs at Government Hospital is the need of the hour. ${ }^{14,15,16,17.18}$

\section{CONCLUSION}

From our study it was evident that headache relief and freedom from headache was better with sumatriptan compared to ergotamine. But recurrence of headache and sustained pain relief was better with ergotamine compared to sumatriptan. Incidence of drug interaction and side effects was also lesser with ergotamine. Ergotamine is economical compared to sumatriptan. Hence physicians may continue to prescribe ergotamine compared to sumatriptan in government setup.

\begin{tabular}{|c|c|c|}
\hline Time (Hours) & \multicolumn{2}{|c|}{ No. of Cases } \\
\hline & Group A & Group B \\
\hline 0.5 & $2(3.50 \%)$ & - \\
\hline 1 & $7(12.28 \%)$ & $1(2.70 \%)$ \\
\hline 1.5 & $13(22.80 \%)$ & $3(8.10 \%)$ \\
\hline 2 & $25(43.85 \%)$ & $6(16.2 \%)$ \\
\hline \multicolumn{3}{|c|}{ Table 1: Showing Distribution of Cases according to } \\
time at which they were pain free \\
\hline
\end{tabular}

\begin{tabular}{|c|c|c|}
\hline Time (Hours) & \multicolumn{2}{|c|}{ No. of Cases } \\
\hline & Group A & Group B \\
\hline 0.5 & $10(17.54 \%)$ & $2(5.40 \%)$ \\
\hline 1 & $23(40.35 \%)$ & $7(18.9 \%)$ \\
\hline 1.5 & $37(64.91 \%)$ & $12(32.43 \%)$ \\
\hline 2 & $41(71.92 \%)$ & $15(40.54 \%)$ \\
\hline $\begin{array}{c}\text { Table 2: Showing Distribution of Cases according to } \\
\text { time at which they achieved pain relief }\end{array}$ \\
\hline
\end{tabular}

\begin{tabular}{|c|c|}
\hline Group & No. of Cases \\
\hline $\mathrm{A}(\mathrm{n}=57)$ & $15(26.3 \%)$ \\
\hline $\mathrm{B}(\mathrm{n}=37)$ & $5(13.5 \%)$ \\
\hline \multicolumn{2}{|c|}{ Table 3: Showing Recurrence of Headache within 24 } \\
hrs in Both Groups \\
\hline
\end{tabular}

\section{REFERENCES}

1. Adams M, Aikman P, Allardyce K. General practitioner clinical trials: treatment of migraine. Practitioner 1971;206:551-4.

2. Cortelli P, Pierangeli G, Corsini R, et al. Pain control in migraine attacks: results from a double-blind, randomized, within-patient, placebo-controlled trial comparing diclofenac- $\mathrm{K}$ and ergotamine-caffeine. Cephalalgia 1996;196:359.

3. Crooks J, Stephen SA, Brass W. Clinical trial of inhaled ergotamine tartrate in migraine.

Br Med J 1964;1:221-4.

4. Dahlof C. Placebo-controlled clinical trials with ergotamine in the acute treatment of migraine. [Review]. Cephalalgia 1993;13:166-71.

5. Dale HH. Physiological actions of ergot. J Physiol. 1906;34(3):163-206.

6. Tfelt-Hansen P, Saxena PR, Dahlof C, Pascual J, Lainez M, Henry $P$, et al.: Ergotamine in the acute treatment of migraine: A review and European consensus. Brain 2000;123:9-18.

7. Boureau F, Kappos L, Schoenen J, et al.: A clinical comparison of sumatriptan nasal spray and dihydroergotamine nasal spray in the acute treatment of migraine. Int J Clin Pract 2000;54:281-286.

8. Visser WH, Terwindt GM, Reines SA, Jiang K, Lines CR, Ferrari MD. Rizatriptan versus sumatriptan in the acute treatment of migraine. A placebo-controlled, doseranging study. Arch Neural. 1996;53:1132-1137. Sciberras DG, Polvino WJ, Gertz BJ, et al. Initial.

9. Plosker GL, McTavish D. Sumatriptan. A reappraisal of its pharmacology and therapeutic efficacy in the acute treatment of migraine and cluster headache. Drugs. 1994;47:622-651.

10. Goadsby P, Zagami A, Donnan G. Oral sumatriptan in acute migraine. Lancet 1991;338(8770):782-783.

11. Brown E, Endersby C, Smith R, et al. The safety and tolerability of sumatriptan: an overview. Eur Neurol 1991;31:339-344.

12. Andersen AR, Tfelt-Hansen P, Lassen NA (1987). The effect of ergotamine and dihydroergotamine or cerebral blood flow in man. Stroke 18:120-123.

13. Hachinski V, Norris JW, Edmeads J, et al. (1978). Ergotamine and cerebral blood flow. Stroke 9:594-596.

14. Meredith JT, Wait S, Brewer KL. A prospective double blind study of nasal sumatriptan vs Ketorolac in migraine headache. Am J Emerg Med 2003;21:173-5.

15. Sandrini G, Färkkilä M, Burgess G, et al. Eletriptan vs sumatriptan: A double-blind placebo-controlled, multiple migraine attack study. Neurology 2002;59:1210-7.

16. Chuthamanee C Suthisisang, Nalinee Poolsup, Nacti S Suksomboon, et al. Meta-analysis of the Efficacy and Safety of Naproxen Sodium in the Acute Treatment of Migraine. Headache. 2010;50:808-818.

17. Jane Mary, Codispoti Joseph R, Min Fu. A Randomized Placebo-controlled Trial of Migraine Headache. Headache 2010;50:819-833.

18. Evers Stefan, et al. European Guidelines Update Drug Treatment of Migraine. Eur J Neurol 2009;16:968-981. 